\title{
Considerações sobre a Causalidade Psíquica e a Escolha na Psicanálise
}

\author{
Germano Quintanilha Costa ${ }^{1}$ \\ Universidade Federal Fluminense \\ Gilberto Gomes \\ Universidade Estadual do Norte Fluminense
}

\begin{abstract}
RESUMO - Freud, ao elaborar sua metapsicologia, buscando explicações para a vida psíquica e seus fenômenos, acaba deparando-se com a velha questão filosófica a respeito do determinismo e do livre arbítrio. É evidente que o prisma pelo qual Freud desenvolveu sua teoria é completamente diferente dos demais campos do saber. No entanto, o enigma era o mesmo. O que significavam, para a teoria psicanalítica, os fenômenos psíquicos estudados por Freud? Eram eles produtos do acaso, da liberdade consciente, ou resultados de algum determinismo? Investigamos neste trabalho como os conceitos psicanalíticos de inconsciente, causalidade psíquica, sobre-determinação e escolha se articulam a essas questões.
\end{abstract}

Palavras-chave: psicanálise, determinismo, escolha, vontade

\section{Considerations on Psychical Causality and Choice in Psychoanalysis}

\begin{abstract}
In developing his metapsychology seeking for explanations of mental life and its phenomena, Freud ends up facing the old philosophical question concerning determinism and free will. It is clear that Freud's approach in developing his theory is completely different from other fields of knowledge. However, the enigma was the same. What did the psychical phenomena studied by Freud mean to psychoanalytical theory? Were they the product of chance, of conscious freedom, or the result of some form of determinism? In this paper we investigate how the psychoanalytical concepts of the unconscious, psychical causality, overdetermination and choice relate to these questions.
\end{abstract}

Keywords: psychoanalysis, determinism, choice, volition

Freud, ao elaborar sua metapsicologia, buscando explicações para a vida psíquica e seus fenômenos, acaba deparando-se também com uma velha questão filosófica a respeito do determinismo e da vontade livre. É evidente que o prisma pelo qual Freud desenvolveu sua teoria é completamente diferente dos demais campos do saber, o que concede, ainda hoje, à psicanálise a especificidade de sua construção teórica no que tange ao conceito do inconsciente. No entanto, o enigma é o mesmo: o que significava para a teoria psicanalítica os fenômenos psíquicos estudados por Freud? Eram eles produtos do acaso, da liberdade consciente, ou resultados de algum determinismo?

Uma análise da teoria freudiana é capaz de demonstrar que, ao longo de sua elaboração teórica, Freud sustentouse em uma forte aposta no determinismo como regente da vida anímica. Em alguns artigos, ele se dedicou, em particular, a comprovar sua hipótese de uma aplicação universal do determinismo aos eventos psíquicos (Freud 1900/1996; 1901/1996; 1905c/1996), chegando a afirmar que "não há nada no psíquico que seja arbitrário ou indeterminado" (Freud, 1901/1996, p. 240). No entanto, o estudo dessa posição teórica freudiana nos conduz a algumas interrogações: podemos tratar essa noção como sendo óbvia na teoria psicanalítica ou devemos reconhecer que estamos

1 Endereço para correspondência: Universidade Federal Fluminense, Pólo Universitário de Campos de Goytacazes, UFF-PUCG, Rua José do Patrocínio, $\mathrm{n}^{\circ} 71$, Centro, Campos dos Goytacazes, RJ, Brasil. CEP: 28.010-385.E-mail:gqcosta@yahoo.com.br diante de uma questão complexa, que, na amplitude dessa teoria, acaba por conviver com outros conceitos?

Ao mesmo tempo em que Freud se apega a um determinismo da vida anímica, ele desenvolve também alguns conceitos que aparentemente produziriam uma controvérsia. Ao falar de escolha de objeto (Objektwahl), escolha do sintoma (Symptomwahl) e escolha da neurose (Neurosenwahl), Freud utiliza-se de uma noção (a de escolha) que tradicionalmente tem sido remetida à noção de liberdade e que, portanto, choca-se com seu determinismo (Laplanche \& Pontalis, 1986). O próprio conceito de associação livre (Freie Assoziation) traria também uma relação paradoxal entre o que seria da ordem da livre escolha de uma idéia com aquilo que seria de uma ordem determinada.

É, justamente, nessa "encruzilhada" da teoria psicanalítica que pretendemos conduzir nossa reflexão, partindo, então, de algumas questões iniciais: Como podemos entender o determinismo psíquico, tal como foi apresentado por Freud? $\mathrm{O}$ que teoricamente sustenta sua hipótese? Se o psiquismo é regido por um determinismo, como entender a questão paradoxal das escolhas?

\section{O Determinismo e o Inconsciente}

Apesar das grandes inovações que seu pensamento trouxe para a psicologia de sua época, Freud, como um homem que não pôde fugir completamente das influências de seu "Zeitgeist", foi também um grande adepto e defensor do 
caráter determinista das explicações científicas. O estudo de sua metapsicologia nos revela que a descoberta e a teorização do inconsciente foi uma empreitada possível, porque Freud pautou sua pesquisa naquilo que constituía, para ele, uma enorme certeza: a aplicação universal do determinismo aos eventos psíquicos. Essa concepção se faz inicialmente presente em sua tentativa de dar explicações neurofisiológicas dos processos psíquicos, notadamente no "Projeto de uma Psicologia", manuscrito de 1895 que só foi publicado em 1950 (Freud, 1950b/1996), mas continua a ter um papel fundamental mesmo após seu abandono de tal tentativa (Gomes, 2005).

Podemos afirmar que, se Freud não fosse um forte adepto do determinismo psíquico, ele jamais poderia ter feito o que fez: conduzir os sintomas neuróticos e toda uma classe de fenômenos psíquicos extremamente banais a uma categoria de fundamental importância em sua pesquisa. A opção determinista também pode ser vista como determinante para sua forte adesão ao conceito de pulsão. É por achar que um fenômeno psíquico não pode nunca resultar puramente de uma razão abstrata, ou de uma pura espontaneidade criativa, que Freud foi buscar no conceito de pulsão uma fonte sempre presente da ocorrência do psíquico (Gomes, 2001).

Apostando que nada que tivesse relação com a vida mental poderia ser fruto do acaso, Freud (1894/1996, 1895/1996) toma primeiramente os sintomas como portadores de um sentido e como reveladores da existência de uma atividade mental inconsciente. Daí em diante, ele não tarda a outorgar à sua teoria uma abrangência muito maior. Através desse determinismo psíquico inconsciente, ele acaba por estender também aos sonhos e aos mais variados tipos de lapsos da consciência, a mesma condição dos sintomas: todos eles são provenientes da ação dos desejos inconscientes, e, como tais, são portadores de um sentido (Freud, 1900/1996, 1901/1996). Desse modo, podemos compreender que a noção de determinismo psíquico em Freud pode ser vista como sincrônica às construções teóricas a respeito do aparelho psíquico e de sua psicodinâmica.

Não se trata de ver a posição determinista como uma posição presente, mas acidental, ou pelo menos contingente, ou seja, como algo não inerente à formulação por Freud de seu conceito de inconsciente. Ao contrário, podemos considerar tal posição como essencial para a própria constituição do conceito psicanalítico de inconsciente (Gomes, 2007).

No entanto, essa não é a única observação possível de ser extraída. Abordar esse tema nos conduz à necessidade de reconhecermos o caráter diferencial da tese freudiana a respeito da causalidade psíquica, uma vez que tal posição situa a teoria psicanalítica numa posição bastante singular. A hipótese com a qual estamos trabalhando é de que a tese freudiana sobre o determinismo psíquico encontra sua significação mais adequada no conceito de sobredeterminação. Dessa forma, o fato de reconhecermos múltiplos fatores causais para os fenômenos psíquicos, é algo que necessariamente diferencia a psicanálise das ciências clássicas no que diz respeito à compreensão e as conseqüências da causalidade. É justamente essa diferenciação que nos permite pensar mais adequadamente sobre a questão da escolha na psicanálise.

\section{A Causalidade Psíquica}

Apesar de o determinismo psíquico ser uma posição assumida por Freud ao longo de toda a sua obra (referências explícitas ao tema podem ser encontradas em Freud, 1901/1996, cap. 12; 1906/1996; 1910/1996, 3ª lição; 1916/1996, 2a conferência), ele não dedicou uma obra exclusiva para o tema do determinismo. No entanto, se nos concentrarmos em alguns conceitos fundamentais de sua obra, poderemos elaborar um esboço sobre a concepção e atuação do determinismo na vida psíquica. Eis, portanto, os temas que nos são preciosos: os múltiplos fatores atuantes na etiologia da neurose, a escolha da neurose, e a noção de a posteriori.

A história da psicanálise tem seu início com os estudos sobre a histeria, principalmente com a tentativa de Freud em decifrar a sua etiologia. No "Rascunho B", escrito em 1893, Freud (1950a/1996) aborda a etiologia da histeria como sendo dependente da articulação de dois fatores: (a) a precondição necessária, sem a qual o estado não pode surgir em absoluto; e (b) os fatores desencadeantes. A precondição necessária, quando atua de modo suficiente, torna inevitável a instauração da afecção nervosa; porém, quando não atua de modo suficiente, ocorre uma disposição para a afecção, que só se manifestará com o acréscimo dos fatores secundários. Assim, "o que falta para o efeito integral na etiologia primária pode ser substituído pela etiologia de segunda ordem; esta, contudo, é dispensável, ao passo que a de primeira ordem é imprescindível" (Freud, 1893/1996, p. 224).

Em 1895, Freud publica um breve artigo, no qual tenta isolar da neurastenia vários estados nervosos e estabelecêlos como uma entidade independente, sob o nome de "neurose de angústia". A ideia central desse artigo era a de que os sintomas da angústia possuíam uma etiologia específica e uniforme, sendo ela de natureza sexual (Freud, 1895b/1996, p. 124). Tendo esse artigo recebido fortes críticas por parte de Loewenfeld, um importante autor no meio médico, Freud escreve então uma réplica, buscando combater a impressão de que sua teoria poderia ser refutada pelas primeiras objeções que apareciam. Em "Resposta às críticas ao meu artigo sobre a neurose da angústia", Freud acaba por desenvolver um quadro bastante complexo da situação etiológica, através do qual pôde demonstrar que “as neuroses são sobredeterminadas, isto é, vários fatores operam conjuntamente em sua etiologia" (Freud, 1895c/1996, p. 130).

A partir da concepção de que a constituição etiológica das neuroses se dá de maneira sobredeterminada, Freud passa a usar a expressão "equação etiológica" para se referir aos vários fatores que precisam ser satisfeitos para que o efeito neurótico ocorra. São eles: precondição, causa especifica, causa concorrente, causa precipitante ou causa desencadeante. A causa precipitante, ou desencadeante, pode ser caracterizada como aquela que aparece por último na equação, de modo que precede imediatamente a emergência do efeito, sendo esse fator cronológico a essência de sua natureza principal. As precondições são os fatores em cuja ausência o efeito nunca se manifestaria, mas que são incapazes de produzi-lo por si mesmos. A causa específica é aquela que nunca está ausente quando o efeito se dá e 
que, em uma certa quantidade e intensidade, é suficiente para produzir efeitos, desde que as precondições também estejam presentes. As causas concorrentes são aquelas que não estão necessariamente presentes todas as vezes, nem podem provocar a manifestação dos sintomas por si mesmas, porém operam em conjunto com as precondições e a causa específica para satisfazer a equação etiológica.

Apesar de afirmar claramente que a precondição e a causa específica são indispensáveis para a equação etiológica, Freud ressalta que nenhuma delas pode se bastar isoladamente como uma causa (Freud, 1895c/1996, p. 134). Retomando a hipótese central de seu artigo, Freud conduz sua réplica afirmando que não há nenhuma relação antitética entre a predisposição hereditária e o fator sexual específico. Em sua opinião, os dois fatores etiológicos se apóiam e se complementam:

O fator sexual só costuma ser atuante nas pessoas que têm também uma tara hereditária inata; a hereditariedade, por si só, usualmente não é capaz de produzir uma neurose de angústia, tendo que aguardar a ocorrência de uma quantidade suficiente da perturbação sexual específica. A descoberta do fator hereditário, por conseguinte, não nos isenta da busca de um fator específico. (Freud, 1895c/1996, p. 136)

Acreditando que a hereditariedade, tomada isoladamente, não pode ajudar-nos a compreender nem o desencadeamento episódico de uma neurose nem a cessação dessa neurose em consequência de tratamento, Freud dá prosseguimento ao estudo dessa questão. Em 1896, Freud publica "A Hereditariedade e a etiologia das neuroses", texto no qual ele vai se dirigir em particular aos seguidores de Charcot, para redigir uma objeção à teoria de que a hereditariedade corresponde à única causa verdadeira e indispensável das afecções neuróticas. A objeção formulada por Freud desenvolve-se no sentido de apresentar a necessidade de se reconhecer a existência tanto de distúrbios nervosos adquiridos quanto de distúrbios hereditários. Vejamos nas suas próprias palavras a forma como ele tece sua crítica, ao mesmo tempo que introduz uma questão importante, a questão da escolha da neurose:

(...) tanto na patogênese neurótica quanto em qualquer outra área, não se pode falar em acaso, deve-se admitir que não é a hereditariedade que rege a escolha do distúrbio nervoso específico a ser desenvolvido no membro predisposto de uma família, mas que há motivos para se suspeitar da existência de outras influências etiológicas de natureza menos incompreensível, que mereceriam então ser chamadas de etiologia específica dessa ou daquela afecção nervosa. Sem a existência desse fator etiológico especial, a hereditariedade nada poderia ter feito. (Freud, 1896/1996a, p. 145)

Apesar de não desconsiderar a hereditariedade como um fator importante na produção de uma neurose, Freud estava cada vez mais convencido de que a hereditariedade nervosa, por si só, era incapaz de produzir as psiconeuroses se faltasse sua etiologia específica, isto é, a excitação sexual precoce. Reconhecendo os vários tipos de quadros neuróticos, Freud se pergunta sobre o que estaria em jogo no fato de um paciente desenvolver certo tipo de neurose em detrimento de outro. Assim, ele fecha seu artigo fazendo o seguinte comentário:

No que concerne à hereditariedade nervosa, (...) Admito que sua presença é indispensável para os casos graves; duvido que seja necessária para os leves, mas estou convencido de que a hereditariedade nervosa, por si só, é incapaz de produzir as psiconeuroses se faltar sua etiologia específica, isto é, a excitação sexual precoce. Creio mesmo que a decisão quanto ao desenvolvimento de uma das duas neuroses, histeria ou obsessões, em determinado caso, não provém da hereditariedade, mas de uma característica especial do evento sexual na tenra infância. (Freud, 1896/1996a, p. 155)

Em "A sexualidade na etiologia das neuroses", Freud (1898/1996) afirma que os resultados de suas pesquisas o conduziam à necessidade de reconhecer que as causas mais imediatas e mais importantes de todos os casos de doença neurótica são encontrados em fatores emergentes da vida sexual. Cabe lembrarmos que Freud está aqui começando a trabalhar com aquela que ficou conhecida como teoria da sedução traumática.

Em um artigo anterior, intitulado "A etiologia da Histeria", Freud (1896b/1996) conduziu sua argumentação no sentido de construir uma explicação detalhada sobre a influência de um evento sexual perturbador na eclosão dos quadros histéricos, podendo este ser considerado, então, pelo seu valor de cena traumática. Freud faz recair sobre a questão do trauma o fator de maior importância na eclosão dos quadros neuróticos.

Contudo, não existe aí uma intenção de substituir pelo sexual todos os outros fatores etiológicos, visto que a teoria do trauma, ou da sedução, não exclui a idéia de uma combinação de fatores. A idéia freudiana é de que os fatores sexuais possuem um papel de destaque na série etiológica (Bernardes, 2000).

É mister reconhecermos, portanto, que a teoria do trauma passa a pôr em destaque uma descontinuidade fundamental entre a causa e o efeito. Compreender, como Freud entende o poder causal que uma certa experiência possui na direção que a neurose do sujeito vai tomar posteriormente é, portanto, extremamente válido, já que o que perseguimos em sua obra é a questão do determinismo psíquico.

O trauma, como passa a ser entendido por Freud, deve ser analisado não somente a partir da lembrança mais recente que o paciente possui sobre a experiência traumática. O primeiro motivo que o leva a reconhecer essa necessidade é o fato de que, trabalhando conforme o procedimento de Breuer, o analista logo se depara com uma dificuldade: é possível que a cena lembrada pelo paciente não tenha nenhuma relação aparente com o sintoma analisado; ou é possível que mesmo tendo alguma relação com o sintoma, ainda assim ela se revele "uma impressão inócua e, via de regra, incapaz de produzir qualquer efeito" (Freud, 1896/1996b, p. 192).

Se a lembrança que é trazida de imediato pelo paciente neurótico não satisfaz a expectativa de compreender o nexo traumático entre a experiência sexual e o sintoma, é porque uma segunda cena estava sendo ignorada pelo método anterior. A teoria do traumatismo psíquico concebe, portanto, a existência de dois tempos separados na produção do trauma. O primeiro tempo é o momento da sedução propriamente dita, ocorrido na infância. Nesse momento, a criança suporta passivamente a investida sexual de um adulto - podendo ser o pai ou outro homem próximo - sob a forma de palavras, gestos ou mesmo de uma agressão sexual. No segundo momento, uma experiência ocorrida após a puberdade, sem 
necessariamente conter qualquer conteúdo sexual, faz por evocar através de um traço associativo a primeira cena. $\mathrm{O}$ trauma envolve, assim, a participação dessas duas cenas, na medida em que é somente a partir dessa segunda cena que a primeira ganha um valor traumático (Freud, 1896a/1996, 1896b/1996).

Ao propor esses dois tempos do traumatismo, Freud já está utilizando uma noção que será de grande importância em toda a sua obra. Através da noção de a posteriori (Nachträglichkeit), ele passa a compreender que a experiência da criança perante a investida sexual não é traumática no momento em que ocorre, mas "só-depois" da puberdade, por meio de algum traço associativo. Esse conceito assume uma importância fundamental para a teoria psicanalítica, pois está na base de toda a compreensão que Freud faz a respeito da questão da temporalidade e da causalidade psíquica (Laplanche \& Pontalis, 1986, p. 441-445).

$\mathrm{O}$ a posteriori permite-lhe estabelecer que existem experiências, impressões e traços mnêmicos que podem ser remodelados posteriormente em função de novas experiências vividas pelo sujeito. Essa remodelagem posterior implica, portanto, a possibilidade de que além de esses traços poderem receber um novo sentido, eles poderão apresentar uma nova eficácia psíquica.

Analisar essa questão é fundamental para o nosso estudo, pois pensar o determinismo na psicanálise é algo que nos remete à necessidade de compreendermos que não se trata de um determinismo linear e estrito. Uma das críticas mais frequentes à psicanálise consiste justamente da acusação de que ela reduz ao passado infantil o conjunto das ações e dos desejos humanos. Contudo, esse tipo de crítica toma por base uma visão completamente rígida e incorreta a respeito da causalidade existente na psicanálise. Se considerarmos que, desde suas primeiras correspondências com W. Fliess, Freud já trabalhava na hipótese de que o mecanismo psíquico havia se estabelecido por estratificação, por meio da qual os materiais presentes sob a forma de traços mnêmicos sofriam, de tempos em tempos, uma reorganização (Freud, 1950c/1996), então esse tipo de acusação mostrar-se-á como ingênua e como fruto de um desconhecimento mais aprofundado da psicanálise (Laplanche \& Pontalis, 1986, p. 442).

Fica claro, portanto, que reconhecendo o caráter a posteriori do funcionamento psíquico, Freud toma o passado como algo flexível, ficando as representações psíquicas do passado sujeitas a um rearranjo promovido pela inscrição de novos traços. Certamente, Freud toma o determinismo como uma hipótese universal para o funcionamento psíquico, mas o que fica mais claro agora é que não se trata de qualquer forma de determinismo, pois assumiu um caminho diferente do paradigma científico de sua época: o modelo de determinismo linear causal da física clássica.

Retornando à questão da teoria do trauma, Freud não se apegou durante muito tempo a sua hipótese de uma sedução real vivida pela criança. De início, o relato de suas pacientes dava a impressão de que, na raiz das neuroses, estavam presentes situações que remetiam a uma sedução real efetuada pelos pais das pacientes. Posteriormente, a experiência mostrou-lhe que ele havia, até então, ignorado o poder das fantasias como criadoras de uma outra realidade, muito mais importante para o psicanalista, a realidade psíquica. Reconhecendo que as cenas de sedução eram fantasias de suas pacientes, ele confessa a W. Fliess, em carta de 1897: "não acredito mais em minha neurótica" (Freud, 1950d/1996, p. 309).

Apesar do abandono da teoria da sedução, é preciso observar que a revisão feita por Freud em suas concepções a respeito da etiologia das neuroses não implicou o abandono da teoria do trauma. Levando à frente essa descoberta, Freud compreende que essas fantasias destinavam-se a encobrir a atividade auto-erótica dos primeiros anos da infância. Com a revelação da atividade sexual infantil por detrás das fantasias, Freud reconhece a constituição herdada do sujeito. Para ele, a disposição e a experiência passam a ser vistas como ligadas em uma unidade etiológica indissolúvel, pois:

(...) a disposição exagera impressões — que de outra forma teriam sido inteiramente comuns e não teriam nenhum efeito

—, de modo a transformá-las em traumas que dão margem

a estímulos e fixações; por outro lado, as experiências

despertam fatores na disposição que, sem elas, poderiam ter ficado adormecidos por muito tempo e talvez nunca se desenvolvessem. (Freud, 1914a/1996, p. 28)

Uma das consequências que a teoria do trauma passou a ter nas explicações freudianas foi a exclusão da hereditariedade do primeiro plano na etiologia dos sintomas neuróticos e o início do desenvolvimento de uma teoria da defesa.

Em “As neuropsicoses de defesa", Freud (1894/1996) formula uma teoria da histeria adquirida, assim como a de outros quadros psíquicos, tais como as fobias, as obsessões e as psicoses. Contrapondo-se às concepções de Janet e de Breuer, Freud adota o termo histeria de defesa, para se referir à sua concepção de que a histeria pode ser considerada como um estado adquirido, uma vez que, nos casos analisados por ele, não se tratava nem de uma grave tara hereditária nem de uma atrofia degenerativa individual. Para ele, a histeria de defesa poderia ser explicada da seguinte forma: as pacientes gozavam de boa saúde mental até o momento em que houve uma ocorrência em sua vida representativa, isto é, "até que seu eu se confrontou com uma experiência, uma representação ou um sentimento que suscitaram um afeto tão aflitivo que o sujeito decidiu esquecê-lo" (Freud, 1894/1996, p. 55).

Assim, as lembranças das experiências traumáticas remetem a situações angustiantes que se mostram incompatíveis com o ego do sujeito, dando início a um procedimento psíquico cuja finalidade seria defender o ego das representações incompatíveis. No entanto, considerando a análise de suas pacientes, Freud adverte: "sei apenas que esse tipo de 'esquecimento' não funcionou (...), mas levou a várias reações patológicas que produziram ou a histeria, ou uma obsessão, uma psicose alucinatória" (Freud, 1894/1996, p. 55).

O mecanismo de defesa passa a ser compreendido como uma tentativa de separação entre as representações psíquicas e os afetos. A defesa torna as representações psíquicas inconscientes, contudo, o destino que o afeto vai encontrar em cada sujeito é o que vai definir a escolha do sintoma: assim se definirá ou uma histeria, ou uma obsessão, ou uma fobia. Frente a isso, podemos observar que é na busca da causalidade, ou da determinação dos sintomas neuróticos, 
que Freud chegou à questão da escolha da neurose. O fato importante a ser ressaltado aqui é a articulação de duas condições aparentemente opostas: a explicação das patologias neuróticas articula a causalidade com a escolha.

Em um artigo intitulado "A disposição à Neurose Obsessiva", Freud (1913/1996) dedica-se com grande ênfase à pesquisa dos fatores que estariam envolvidos no problema da escolha da neurose. Considerando sua pesquisa etiológica anterior, ele foi levado a dividir os determinantes patogênicos envolvidos nas neuroses em dois tipos: o "constitucional" $\mathrm{e}$ o "acidental". O primeiro constitui os determinantes que a pessoa traz consigo para a sua vida, enquanto o segundo são aqueles a vida traz para a pessoa, sendo que somente através de uma operação combinada que o quadro patológico pode ser estabelecido (Freud, 1913/1996, p. 341).

Seguindo esse raciocínio, Freud busca responder à questão da escolha da neurose enfatizando o poder das disposições. Porém, é preciso levar em consideração que, quando Freud utiliza o termo disposições, ele não está se referindo apenas a algo puramente hereditário. Como lembra o editor em nota de rodapé, no próprio artigo "A disposição à neurose obsessiva" (Freud 1913/1996), o autor amplia o alcance desse termo, em trabalhos posteriores, passando este a se referir também aos efeitos da experiência na infância.

Mas onde a fonte dessas disposições se faz acessível ao conhecimento psicanalítico? Para Freud, a fonte dessas disposições deve ser procurada naquilo que ele chamou de pontos de fixação da libido, questão que já havia sido estudada por ele anteriormente nos "Três ensaios sobre a teoria da sexualidade" (1905b/1996). Postulando que, em cada fase do desenvolvimento psicossexual, existe a possibilidade de surgir um ponto de fixação da pulsão, Freud propõe que a compreensão da escolha do sintoma deve levar em consideração a fixação do sujeito em determinadas etapas de seu desenvolvimento.

Posteriormente, em uma conferência intitulada "Algumas idéias sobre desenvolvimento e regressão - etiologia", Freud (1917/1996) elabora mais adequadamente essa relação entre o desenvolvimento psicossexual e a causação das neuroses. Partindo da constatação de que a função libidinal sofre uma prolongada evolução até que possa, por fim, ser posta a serviço da reprodução, Freud ressalta que, nesse desenvolvimento, existe a possibilidade de ocorrência de dois "perigos": primeiro, a inibição, e, segundo, a regressão.

Durante o desenvolvimento da função libidinal, é possível que algumas partes das tendências sexuais permaneçam estagnadas em estágios anteriores, caracterizando a fixação da pulsão. Por outro lado, é igualmente possível que certas tendências sexuais, que conseguiram prosseguir para os estádios posteriores, também retornem a um desses estágios precedentes fixados, o que constitui o fenômeno da regressão. Para Freud, as tendências sexuais tomam o caminho da regressão quando elas encontram fortes obstáculos ao exercício de sua função, ou seja, quando a obtenção de satisfação torna-se impedida por algum obstáculo externo (Freud, 1917/1996, p. 343).

Pela maneira que concebe a fixação e a regressão, vemos que, no pensamento freudiano, esses dois processos não podem ser compreendidos como sendo independentes um do outro. Assim, podemos considerar plausível que, quanto mais intensas são as fixações da pulsão, mais prontamente ela fugirá das dificuldades externas, adotando como saída o processo regressivo. Propondo que a compreensão da relação existente entre a fixação e a regressão representa uma via segura e fértil para compreensão da formação das neuroses, Freud postula a existência de dois tipos de regressão. O primeiro tipo diz respeito a um retorno aos objetos que foram inicialmente catexizados pela libido, os quais a psicanálise já havia identificado como sendo de natureza incestuosa, sendo esse o caso que se faz presente na neurose histérica. O segundo tipo, presente na neurose obsessiva, é aquele no qual há uma regressão ao estágio preliminar da organização sádico-anal (Freud, 1917/1996, p. 345).

A fim de tornar mais clara essa relação entre a etiologia das neuroses e os mecanismos da fixação e da regressão, Freud introduz a questão da frustração. As pessoas adoecem de neurose quando por algum motivo foram impedidas de satisfazer sua libido, dando origem a um sentimento de frustração. Dessa forma, a psicanálise passa a enxergar na fixação libidinal e na frustração fatores causais de grande importância na etiologia das neuroses, uma vez que respectivamente elas representam os fatores constitucionais e acidentais. A fixação da libido constitui o fator endógeno, ou predisponente, enquanto as frustrações vão constituir os fatores externos, ou acidentais.

Frente a esse cenário, Freud afirma que a etiologia das neuroses financiou por um bom tempo um debate improdutivo a respeito das seguintes questões: as neuroses são doenças exógenas ou endógenas? Elas são resultado dos fatores constitucionais ou das experiências acidentais, traumáticas? Formular a questão desse modo é extremamente incorreto, por isso ele afirma que ambos os fatores são igualmente indispensáveis e, no que tange à causalidade das neuroses, quando a relação entre os fatores não é precisamente a mesma, pelo menos é muito similar (Freud, 1917/1996, p. 350). Portanto, assim como um pai e uma mãe são responsáveis pela concepção de um bebê, Freud postula que os fatores constitucionais e acidentais interagem em um plano causal formando uma equação etiológica. Desse modo, não faz sentido algum supor que um dos fatores tenha mais importância do que o outro no que tange à causalidade das neuroses.

Considerando, então, o percurso realizado até aqui, constatamos que a noção de equação etiológica, apesar das diferentes explicações que passou a receber ao longo do tempo, teve preservada, até o fim, aquela que constituía sua idéia original, isto é, a hipótese freudiana de que múltiplos fatores atuam conjuntamente na causalidade da neuroses. Foi, portanto, sob uma forte convicção na sobredeterminação dos fenômenos psíquicos que Freud se debruçou sobre a questão da causalidade, posição essa que passa a conceder ao termo escolha novos contornos quanto ao seu significado e atuação.

\section{O Debate entre Determinismo e Liberdade}

Em "Cinco lições de Psicanálise", analisando os obstáculos que frequentemente ofereciam resistências à aceitação das ideias psicanalíticas, Freud (1910/1996) reconhece que uma delas é a falta de hábito das pessoas em 
contar com um rigoroso determinismo da vida mental, o qual não conhece exceção. Sendo assim, Freud enxerga o lugar do psicanalista a partir do seguinte prisma: "notarão desde logo que o psicanalista se distingue pela rigorosa fé no determinismo da vida mental. Para ele não existe nada insignificante, arbitrário ou casual nas manifestações psíquicas" (Freud, 1910/1996, p. 50).

Ernest Jones, aluno e biógrafo de Freud, revela que a crença freudiana na universalidade da lei natural e a descrença na ocorrência de milagres ou de atos espontâneos foram profundamente influenciadas pela sua formação científica inicial. Para ele, "Freud nunca vacilou nessa atitude e toda a sua pesquisa sobre o funcionamento da mente é inteiramente baseada na crença em uma cadeia regular de eventos mentais", (Jones, 1989, p. 367).

Em “A Interpretação dos sonhos", Freud (1900/1996) já abordava a questão do determinismo psíquico quando fala do equívoco cometido pelos autores precedentes com relação às modificações ocorridas com os sonhos, ao acreditarem em uma arbitrariedade desse processo. Opondo-se a estes autores, ele afirma que eles subestimaram a extensão do determinismo nos eventos psíquicos, já que:

(...) não há neles nada de arbitrário (...) De modo bastante geral, pode-se demonstrar que, se um elemento deixa de ser determinado por certa cadeia de pensamentos, sua determinação é imediatamente comandada por outra. (Freud, 1900/1996, p. 546)

Em "Fragmento da análise de um caso de histeria", Freud (1905a/1996) novamente entra no mérito do determinismo. Passado alguns anos desde as primeiras formulações sobre a patogênese dos sintomas histéricos e sobre os seus processos psíquicos, Freud propôs-se a fundamentá-las através de um relato pormenorizado de um caso clínico e de seu tratamento, o famoso Caso Dora. Nas notas preliminares desse relato, Freud faz uma antecipação e informa ao leitor que seu "objetivo neste caso clínico era demonstrar a estrutura íntima da doença neurótica e o determinismo de seus sintomas." (Freud, 1905a/1996, p. 19).

Em “A psicanálise e a determinação dos fatos nos processos jurídicos", Freud (1906/1996) aborda a questão do determinismo quando foi convidado a colaborar, através de suas pesquisas, na elucidação de uma técnica por via da qual os juristas pretendiam combater a falta de fidedignidade das declarações feitas pelos réus e testemunhas. Freud afirma que essas experiências de associação só se tornaram significativas e proveitosas quando, em Zurique, Bleuler e Jung começaram a trabalhar com a hipótese de que a reação à palavra-estímulo não podia ser fruto do acaso, mas devia ser determinada pelo conteúdo ideativo presente na mente do sujeito que reagia. A importância desses estudos, para Freud, encontrava-se no fato de que eles eram completamente compatíveis com o estudo que ele havia realizado, em 1901, sobre as parapraxias (Fehlleistungen ou atos falhos), por meio do qual demonstrou serem de determinação rígida toda uma série de atos que se acreditava serem imotivados, contribuindo, assim, em certo grau, para limitar o fator arbitrário na psicologia.

Apesar de podermos identificar a posição que Freud assume perante a questão do determinismo e da vontade livre ao longo dessas várias passagens, foi particularmente em "A Psicopatologia da vida cotidiana" (1901) que ele se dedicou à realização de um estudo mais aprofundado sobre esse tema. No prefácio do editor, para essa obra, somos informados de que a especial simpatia com que Freud encarava os atos falhos se devia, sem dúvida, ao fato de eles serem, juntamente com os sonhos, o que lhe permitiu estender à vida psíquica normal as descobertas que antes fizera em relação às neuroses. Por meio desses fenômenos simples e facilmente explicáveis, Freud pôde demonstrar a validade de dois dos seus mais importantes postulados. Primeiro, ele pôde demonstrar a existência de dois modos distintos de funcionamento psíquico, por ele descrito como processos primário e secundário. Segundo, o exame dos atos falhos oferecia um apoio convincente a sua crença na aplicação universal do determinismo aos eventos psíquicos. É nessa tese que ele insiste no último capítulo do livro: "teoricamente, seria possível descobrir os determinantes psíquicos de cada um dos menores

Foi no último capítulo dessa obra que Freud condensou todo o conhecimento proveniente dos estudos dos vários tipos de parapraxias, chegando à compreensão geral de que certas insuficiências de nosso funcionamento psíquico e certos desempenhos aparentemente inintencionais, quando submetidos à investigação psicanalítica, revelam ter motivos válidos e ser determinados por motivos desconhecidos pela consciência (Freud, 1901/1996: 237).

Em seguida, Freud desenvolve uma argumentação que, a nosso ver, constitui um dos momentos em que ele melhor definiu seu ponto de vista sobre o debate entre livre-arbítrio e determinismo. Segundo ele, muitas pessoas contestam a suposição de um determinismo psíquico invocando um sentimento especial de que existe um livre-arbítrio. No entanto, até mesmo esse sentimento "normal" é passível de explicação, pois existe algo que o justifica:

Pelo que posso observar, porém, ele não se manifesta nas grandes e importantes decisões da vontade: nessas ocasiões, tem-se antes o sentimento de compulsão psíquica, e de bom grado se recorre a ele. ("Aqui me posiciono, não tenho outra escolha.") $)^{1}$ Em contrapartida, é justamente nas decisões indiferentes e insignificantes que se prefere asseverar que teria sido igualmente possível agir de outra maneira, que se agiu por uma vontade livre e não motivada. (Freud, 1901/1996, p.250)

De acordo com essa análise, a sensação humana de agir com base em uma vontade livre é experimentada apenas em certos momentos da vida. Realmente, se analisarmos nossos sentimentos cotidianos, veremos que, de fato, existe uma diferença qualitativa, em termos de experiência subjetiva, quando estamos diante de uma situação na qual nossa decisão terá consequências importantes para nossa vida ou para aqueles que nos cercam e quando estamos diante de uma situação cujas conseqüências são banais e comuns.

É exatamente essa condição que Freud quer abordar na citação que destacamos anteriormente. Lembrando da célebre declaração atribuída a Martinho Lutero “Aqui me posiciono, não tenho outra escolha", ele justifica sua afirmativa de que nas decisões extremamente significativas da vida, o sujeito parece não considerar que agiu por uma vontade própria e

1 A frase citada por Freud é atribuída a Martinho Lutero, em sua resposta na Dieta de Worms (1521), onde lhe foi pedido que renegasse suas teses 
livre. Em seguida, encontramos uma nova passagem também bastante reveladora. Baseando-se nessa distinção, que comentamos logo acima, Freud afirma que, de acordo com suas análises, não é necessário contestarmos a legitimidade do sentimento de convicção sobre a existência de um livrearbítrio, pois:

Quando levamos em conta a distinção entre motivação consciente e motivação inconsciente, nosso sentimento de convicção nos informa que a motivação consciente não se estende a todas as nossas decisões motoras (...) Mas o que é assim liberado por um lado recebe sua motivação do outro, do inconsciente, e desse modo o determinismo no psíquico prossegue ainda sem nenhuma lacuna. (Freud, 1901/1996, p. 250)

De acordo com essa afirmativa, estamos em condições de considerar que, mesmo sendo o sentimento do livre-arbítrio algo que encontra sentido na vida consciente, ele logo perde seu espaço quando passamos a dar crédito à existência de uma vida psíquica que não se organiza de maneira caótica e misteriosa, mas sim de maneira determinada, na qual se fazem presentes leis e princípios. Pensar no inconsciente, tal como Freud o postulou, é pensar que, mesmo quando a consciência deixa o sujeito livre de suas funções, ainda assim o sujeito não passa a estar totalmente entregue a uma situação psíquica de liberdade, já que o funcionamento inconsciente não deixou de estar atuante.

\section{O Sujeito Entre o Determinismo e a Escolha}

Com "A psicopatologia da vida cotidiana", Freud (1901/1996) não só enxergou uma ampla atuação do determinismo inconsciente, como estreitou a tênue linha que separava a condição mental "normal" e "patológica". Assim, a psicanálise fundou-se como uma ciência do psiquismo admitindo a existência de forças inconscientes que prevalecem sobre as conscientes, de maneira a revelar que o inconsciente vem restringir a liberdade consciente do sujeito, seja em grau maior, nos quadros ditos "patológicos", seja em grau menor, nas chamadas psicopatologias da vida cotidiana.

Em geral, os defensores da existência de um livre arbítrio costumam justificar sua crença fazendo parecer plausível que o homem apenas não é livre quando mentalmente está sujeito a compulsões e patologias mentais. Quanto a esse aspecto, a psicanálise parece vir introduzir um fator complicador para esse tipo de argumento. Ao igualar os processos psíquicos que existem nos quadros "patológicos" e "normais", a psicanálise parece não deixar brechas para a suposição de que, em algum segmento de nosso psiquismo, possamos estar absolutamente livres de influências determinantes de outros elementos psíquicos. Nossa vida cotidiana, dita "normal", está impregnada de formações do inconsciente, expondo-nos ao fato de que, mesmo não estando sujeito a grandes patologias, ainda assim não podemos considerar nossas ações, comportamentos e intenções como sendo de uma natureza completamente livre.

Considerando a dimensão terapêutica da psicanálise, precisamos reconhecer que estamos falando de uma técnica, uma práxis, cuja aplicação tem a capacidade de tornar o sujeito cada vez menos "escravizado" pela tirania de seu inconsciente. Isso pode ser sustentado quando Freud fala sobre a possibilidade de o sujeito vir a fazer uma "rejeição por julgamento", ou, pelos momentos que o sujeito atravessa ao longo de uma análise, a saber: repetir, recordar e elaborar (Freud, 1914b/1996).

Isso, no entanto, não nos permite exagerar a ponto de podermos acreditar em um poder completo de uma espécie de "cura libertacional" da psicanálise. A psicanálise logrou êxito ao demonstrar que o sistema inconsciente, além de maior sistema psíquico, é, também, um sistema ineliminável. Freud nos demonstrou que nem tudo que é inconsciente foi fruto do recalque, porque existem no inconsciente impulsos que possivelmente nunca chegarão a se tornar conscientes para o sujeito, não podendo assim serem submetidos às forças do recalque posterior (Nachdrängen).

Sabemos que aquilo que a psicanálise pode oferecer é a criação, por parte do sujeito, de um novo processo conciliatório entre as suas forças psíquicas, disponibilizando, dessa forma, uma saída diferente daquela que o sintoma estava anteriormente encarregado de representar. Assim, se tivéssemos que pensar em algum tipo de capacidade de escolha, só poderíamos pensar em uma escolha onde a liberdade é bastante restrita, algo do tipo de uma liberdade "relativa".

O sujeito que se lança em uma análise, é, portanto, aquele que vai, por meio da palavra e do deslizamento das representações - que até então estavam no centro de suas vivências traumáticas e recalcadas -, direcionar as forças psíquicas para uma saída que seja possível e menos angustiante para ele. Cabe destacarmos o sentido que estamos dando a essa saída "possível”, porque, nesse ponto, somos impossibilitados pela experiência psicanalítica de acreditarmos na reconfortante possibilidade de encontrar uma saída "ideal” ou "perfeita” para nossas angústias, algo que pudesse se assemelhar ao sonho humano de dar ao nosso destino o fim que melhor nos convém.

Partindo, então, da constatação de que "possível" não é o mesmo que "perfeito" ou "ideal", o inconsciente deve ser enxergado como uma dimensão psíquica inesgotável na vida humana. Nosso poder de "elaboração" é relativo e limitado, dando-nos a constatação de que, se Freud posicionou-se como um adepto do determinismo, isso não o remeteu a congelar o psiquismo humano em uma impossibilidade total de transformação.

Se o sujeito freudiano é determinado por suas forças inconscientes, a capacidade que ele tem de se libertar dessas formações patológicas não poderá ser considerada como um poder de liberdade propriamente dita. Em "Estudos sobre histeria" (1895a/1996), no capítulo em que falava sobre a psicoterapia da histeria, Freud faz a seguinte observação:

Quando prometo a meus pacientes ajuda ou melhora por meio de um tratamento catártico, muitas vezes me defronto com a seguinte objeção: "Ora, o senhor mesmo me diz que minha doença provavelmente está relacionada com as circunstâncias e os acontecimentos de minha vida. O senhor, de qualquer maneira, não pode alterá-los. Como se propõe ajudar-me, então?" E tem-me sido possível dar esta resposta: "Sem dúvida o destino acharia mais fácil do que eu aliviá-lo de sua doença.

2 Sobre esse conceito freudiano (Urteilsverwerfung), ver Gomes (1985). 
Mas você poderá convencer-se de que haverá muito a ganhar se conseguirmos transformar seu sofrimento histérico numa infelicidade comum. Com uma vida mental restituída à saúde, você estará mais bem armado contra essa infelicidade". (Freud, 1895a/1996, p. 316)

Portanto, um dos pontos mais significativos de nossa trajetória é a de compreender que o determinismo da psicanálise não pode ser comparado ao determinismo da física clássica. Nosso estudo indica que, para a psicanálise, além da causalidade, existe a escolha, embora sejamos obrigados a encarar a realidade de que essa escolha mostra-se como restrita e não totalmente livre.

Nosso estudo nos permite pensar que, segundo a forma como o psiquismo é estruturado, com suas leis e mecanismos, ele concede ao sujeito somente algumas possibilidades de ressignificação. Contudo, precisamos de cautela. Lembremos que algumas não quer dizer todas. O sujeito ressignificará as impressões inconscientes, que vinham lhe trazendo sofrimentos, porém, precisamos considerar que esse novo campo de produção de sentido, não poderá fugir de certas dimensões que foram adquiridas pelo sujeito naquilo que foi da ordem de uma experiência de vida.

Como Freud mostrou com o a posteriori, o sentido surgirá não somente com as experiências passadas, nem somente com as experiências mais recentes, mas necessariamente em um elo de associação entre as duas. A outra cena, aquela que é inconsciente para o sujeito, e que constitui os primeiros traços de impressão no psiquismo, estará sempre fazendo frente para o sujeito, não podendo este rejeitar definitivamente a existência dela, seja através do recalque, seja através da rejeição de sua crítica consciente. O que o sujeito pode é buscar novas perspectivas possíveis para o seu olhar.

\section{Conclusão}

Exploramos dentro da teoria psicanalítica as implicações que o conceito de inconsciente trouxe para o debate envolvendo a vontade livre e o determinismo. O estudo da teoria psicanalítica nos demonstrou, portanto, que a aposta freudiana em um determinismo psíquico inconsciente conduziu a psicanálise ao lugar de uma "ciência" do psiquismo, na qual se admite a existência de forças inconscientes que prevaleçam sobre as conscientes, de maneira a revelar que o inconsciente vem restringir a liberdade consciente do sujeito, seja em grau maior, nos quadros ditos "patológicos", seja em grau menor, em eventos da chamada psicopatologia da vida cotidiana.

A psicanálise parece vir introduzir um fator complicador para aqueles que postulam a vontade livre justificando que o homem apenas não é livre quando está mentalmente sujeito a compulsões e patologias mentais. Ao igualar os processos psíquicos existentes nos quadros "patológicos" e "normais", a psicanálise parece não deixar brechas para a suposição de que, em algum segmento de nosso psiquismo, possamos estar absolutamente livres de influências determinantes de outros elementos psíquicos.

O sujeito que se lança em uma psicanálise é, portanto, aquele que vai poder, através da palavra e do deslizamento das representações, direcionar as forças psíquicas para uma saída que seja possível e menos angustiante para ele. Isso nos fornece a constatação de que, se Freud posicionou-se o tempo todo como um adepto do determinismo, por outro lado, isso não o levou a congelar o psiquismo humano em uma impossibilidade total de transformação, mesmo sendo preciso reconhecer que é relativo e limitado nosso poder de "elaboração".

No entanto, se o sujeito é determinado por suas forças inconscientes, a capacidade que ele tem de se libertar dessas formações patológicas não pode ser considerada como um poder de liberdade propriamente dita. Nossa pesquisa demonstrou que, para a psicanálise, além da causalidade, existe a escolha, embora sejamos obrigados a encarar a dura realidade de que essa escolha mostra-se como restrita e não totalmente livre.

\section{Referências}

Bernardes, M. C. N. (2000). O sujeito entre a sobredeterminação e escolha. (Dissertação de Mestrado não publicada). Programa de Pós-Graduação em Teoria Psicanalítica, Instituto de Psicologia, Universidade Federal do Rio de Janeiro, Rio de Janeiro, Brasil.

Freud, S. (1996). Rascunho B: A etiologia das neuroses. In Obras psicológicas completas de Sigmund Freud, ESB (vol. I). Rio de Janeiro: Imago. (Trabalho original publicado em 1893)

Freud, S. (1996). As neuropsicoses de defesa. In Obras psicológicas completas de Sigmund Freud, ESB (vol. III). Rio de Janeiro: Imago. (Trabalho original publicado em 1894)

Freud, S. (1996). Estudos sobre a Histeria. In Obras psicológicas completas de Sigmund Freud, ESB (vol. II). Rio de Janeiro: Imago. (Trabalho original publicado em 1895a)

Freud, S. (1996). Sobre os fundamentos para destacar da neurastenia uma síndrome específica denominada neurose de angústia. In Obras psicológicas completas de Sigmund Freud, ESB (vol. III). Rio de Janeiro: Imago. (Trabalho original publicado em 1895b)

Freud, S. (1996). Resposta às críticas a meu artigo sobre a neurose da angústia. In Obras psicológicas completas de Sigmund Freud, ESB (vol. III). Rio de Janeiro: Imago. (Trabalho original publicado em 1895c)

Freud, S. (1996). A Hereditariedade e a etiologia das neuroses. In Obras psicológicas completas de Sigmund Freud, ESB (vol. III). Rio de Janeiro: Imago. (Trabalho original publicado em 1896a)

Freud, S. (1996). A etiologia da Histeria. Publicação original. In Obras psicológicas completas de Sigmund Freud, ESB (vol. III). Rio de Janeiro: Imago. (Trabalho original publicado em 1896b)

Freud, S. (1996). A sexualidade na etiologia das neuroses. In Obras psicológicas completas de Sigmund Freud, ESB (vol. III). Rio de Janeiro: Imago. (Trabalho original publicado em 1898)

Freud, S. (1996). A interpretação dos sonhos e Sobre os sonhos. In Obras psicológicas completas de Sigmund Freud, ESB (vol. IV e V). Rio de Janeiro: Imago. (Trabalho original publicado em 1900)

Freud, S. (1996). Sobre a psicopatologia da vida cotidiana. In Obras psicológicas completas de Sigmund Freud, ESB (vol. VI). Rio de Janeiro: Imago. (Trabalho original publicado em 1901) 
Freud, S. (1996). Fragmento da análise de um caso de histeria. In Obras psicológicas completas de Sigmund Freud, ESB (vol. VII). Rio de Janeiro: Imago. (Trabalho original publicado em 1905a)

Freud, S. (1996). Três ensaios sobre a teoria da sexualidade. In Obras psicológicas completas de Sigmund Freud, ESB (vol. VII). Rio de Janeiro: Imago. (Trabalho original publicado em 1905b)

Freud, S. (1996). Os Chistes e sua Relação com o Inconsciente. In Obras psicológicas completas de Sigmund Freud, ESB (vol. VIII). Rio de Janeiro: Imago. (Trabalho original publicado em 1905c)

Freud, S. (1996). A psicanálise e a determinação dos fatos nos processos jurídicos. In Obras psicológicas completas de Sigmund Freud, ESB (vol. IX). Rio de Janeiro: Imago. (Trabalho original publicado em 1906).

Freud, S. (1996). Cinco lições de psicanálise. In Obras psicológicas completas de Sigmund Freud, ESB (vol. XI). Rio de Janeiro: Imago. (Trabalho original publicado em 1910)

Freud, S. (1996). A disposição à Neurose Obsessiva. In Obras psicológicas completas de Sigmund Freud, ESB (vol. XII). Rio de Janeiro: Imago. (Trabalho original publicado em 1913)

Freud, S. (1996). A história do movimento psicanalítico. In Obras psicológicas completas de Sigmund Freud, ESB (vol. XIV). Rio de Janeiro: Imago. (Trabalho original publicado em 1914a)

Freud, S. (1996). Recordar, repetir e elaborar. In Obras psicológicas completas de Sigmund Freud, ESB (vol. XII). Rio de Janeiro: Imago. (Trabalho original publicado em 1914b)

Freud, S. (1996). O Inconsciente. In Obras psicológicas completas de Sigmund Freud, ESB (vol. XIV). Rio de Janeiro: Imago. (Trabalho original publicado em 1915)
Freud, S. (1996). Conferências introdutórias sobre a psicanálise. In Obras psicológicas completas de Sigmund Freud, ESB (vol. $\mathrm{XV}$ ). Rio de Janeiro: Imago. (Trabalho original publicado em 1916)

Freud, S. (1996). Conferência XXII: Algumas ideias sobre desenvolvimento e regressão - etiologia. In Obras psicológicas completas de Sigmund Freud, ESB (vol. XVI). Rio de Janeiro: Imago. (Trabalho original publicado em 1917)

Freud, S. (1996). Rascunho B: A etiologia das neuroses. In Obras psicológicas completas de Sigmund Freud, ESB (vol. I). Rio de Janeiro: Imago. (Trabalho original publicado em 1950a)

Freud, S. (1996). Projeto de uma psicologia científica. In Obras psicológicas completas de Sigmund Freud, ESB (vol. I). Rio de Janeiro: Imago. (Trabalho original publicado em 1950b).

Freud, S. (1996). Carta 52. In Obras psicológicas completas de Sigmund Freud, ESB (vol. I). Rio de Janeiro: Imago. (Trabalho original publicado em 1950c).

Freud, S. (1996). Carta 69. In Obras psicológicas completas de Sigmund Freud, ESB (vol. I). Rio de Janeiro: Imago. (Trabalho original publicado em 1950d).

Gomes, G. (1985). Édipo: Recalcado ou condenado? Cadernos de Psicanálise (CPRJ), 5, 24-28.

Gomes, G. (2001). Os dois conceitos freudianos de 'Trieb'. Psicologia: Teoria e Pesquisa, 17(3), 239-245.

Gomes, G. (2005). O problema mente-cérebro em Freud. Psicologia: Teoria e Pesquisa, 21(2), 149-155.

Gomes, G. (2007). A gênese do conceito freudiano de inconsciente. Estudos de Psicologia, 12(1), 31-36.

Jones, E. (1989). A vida e a obra de Sigmund Freud. Vol. 1: Os anos de formação e as grandes descobertas. Rio de Janeiro: Imago.

Laplanche, J., \& Pontalis, J.-B. (1986). Vocabulário da psicanálise. São Paulo: Martins Fontes. 